\title{
ISSN: 1679-3013 \\ D.O.I.: 10.5914/to.2011.0049 \\ EDUCAÇÃO AMBIENTAL COMO INSTRUMENTO DE GESTÃO COMUNITÁRIA DE ECOSSISTEMAS MANGUEZAIS DO CANAL DE SANTA CRUZ (PE, BRASIL)
}

\author{
Maryse Nogueira PARANAgUÁ \\ Viviane Lúcia dos Santos ALMEIDA \\ Mauro de MELO JÚNIOR \\ Marcos Souto ALVES
}

Henrique Monteiro de BARROS

Recebido em: $24 / 03 / 2010$

Aceito em: $25 / 11 / 2010$

\begin{abstract}
Environmental education is still incipient, despite the fact that it is a powerful tool to mobilize various segments of the society. This paper presents a synthesis of the some environmental education programs carried out in the mangrove communities of the Santa Cruz Channel, aiming prepare groups for activities related to conserving the coastal ecosystems that are the basis of this population's traditional sustenance. In this context, workshops were held for the sons of fishermen from the mangrove human community, establishing a connection between the local community and the formal knowledge that was transmitted. The first phase was dedicated to training local guides in order to add to the knowledge concerning the mangroves of the region, integrating community and environment. Among other activities, students made brochures about the acquired knowledge, produced zoological collections emphasizing the economical species of the region and created cartoon characters and stories. Secondarily, ponds with the red mangrove Rhizophora mangle L. were created in some houses near mangrove areas. By connecting theory and practice, students were able to understanding better the dynamics of the mangrove system and the ecological importance of environmental conservation, based on previous knowledge. At the end of the activities, the young public assimilated the most part of the content presented, and become aware of the importance of the conservation and preservation of this environment.
\end{abstract}

Keywords: traditional communities, environmental education, Northeastern Brazil.

\section{RESUMO}

A prática da educação ambiental é ainda incipiente, apesar de ser um importante instrumento mobilizador dos vários segmentos da sociedade. Este trabalho apresenta uma síntese das experiências realizadas nos manguezais do Canal de Santa Cruz, Pernambuco - Brasil, objetivando a formação de competências locais para a avaliação e monitoramento das condições ambientais de ecossistemas costeiros que constituem a base de seu sustento tradicional. Foram oferecidas oficinas de transferência de conhecimento aos filhos de pescadores provenientes de comunidades carentes próximas aos manguezais da região, possibilitando um contato direto dos grupos locais com o conhecimento formal transmitido. O objetivo geral destes programas foi formar guias ambientais para multiplicação dos conhecimentos. Destacaram-se entre as atividades realizadas: confecção de cartilhas didáticas; produção de caixas zoológicas com ênfase às espécies de importância econômica para a região; criação de histórias em quadrinhos com temas trabalhados em sala de aula; visitas ao campo e coleta didática de organismos. Secundariamente, realizou-se a introdução de viveiros de mudas de mangue-vermelho Rhizophora mangle L. em habitações localizadas em áreas de

Contatos: Universidade Federal Rural de Pernambuco, Av. Dom Manuel de Medeiros, s/n, Dois Irmãos, Recife - PE, Brasil. CEP. 52.171-900.

e-Mails. marysep@uol.com.br; mmelojunior@gmail.com; marcosouto@uol.com.br; hdbarros@terra.com.br 
PARANAGUÁ, M. N. et. all. Educação ambiental como instrumento de gestão comunitária de ecossistemas manguezais do canal de Santa Cruz (PE, Brasil).

manguezal. Aliando teoria e prática, permitiu-se que os alunos desenvolvessem uma melhor compreensão da dinâmica do ecossistema manguezal, seu papel ecológico e a importância de sua conservação, a partir de seus conhecimentos prévios. Ao término das atividades, observamos que os jovens assimilaram grande parte dos conhecimentos transmitidos, despertando em cada um a preocupação pela conservação e preservação dos recursos dos manguezais da região.

Palavras-chave: Comunidades tradicionais, educação ambiental, manguezal, Nordeste do Brasil.

\section{INTRODUÇÃO}

O manguezal é um ecossistema onde as marés e as correntes costeiras provocam as oscilações e onde plantas e animais adaptam-se às variações químicas, físicas e biológicas características deste ambiente (Field 1996). Para Vannucci (1999), a composição específica e a estrutura das "melhores" florestas de mangues variam em função da biogeografia e das condições ambientais locais. Seria difícil descrever uma floresta de mangue "típica", mostrando que cada manguezal é único.

O litoral do Estado de Pernambuco possui uma extensão de $187 \mathrm{Km}$, estando localizado entre as coordenadas $7^{\circ} 32^{\prime}-8^{\circ} 56^{\prime} \mathrm{S}$ e $34^{\circ} 49^{\prime}-35^{\circ} 11^{\prime} \mathrm{W}$. No litoral norte, destaca-se o complexo estuarino-costeiro do Canal de Santa Cruz, com vastas áreas de manguezais associado aos estuários de vários rios que desembocam nessa região. Este complexo pode ser considerado como um dos mais importantes e estudados do litoral do estado, representando uma unidade ecológica de grande significado sócio-econômico, em virtude de sua produtividade natural e biodiversidade, apresentando um conjunto de habitats para as espécies de importância pesqueira (Barros et al. 1999; Barros e Eskinazi-Leça 2000). Segundo estes últimos autores, a diversidade florística está representada por aproximadamente 214 espécies, incluindo quatro espécies de mangues.

O manguezal do Canal de Santa Cruz, objeto deste estudo, é do tipo ribeirinho, estendendo-se por todo o canal, principalmente nos estuários da margem oeste. Recobre uma área de aproximadamente 1220 hectares, e a vegetação está constituída basicamente por três espécies: Rhizophora mangle L. (mangue vermelho), Avicennia shaueriana Staf. e Leechosan (mangue preto) e Laguncularia racemosa Gaetn. (mangue branco), sendo Rizophora mangle a espécie dominante. Conocarpus erectus é a espécie menos freqüente, sendo encontrada apenas em locais mais elevados (Schuler et al. 2000).

A fauna dos três principais grupos estudados na região está composta por 564 espécies, destacando-se 134 de moluscos, 161 de crustáceos e 140 de peixes (Barros e Eskinazi-Leça 2000). Em particular para o zooplâncton, observa-se que este grupo tem um relevante papel na economia da região, uma vez que grande parte do meroplâncton é representada por larvas de espécies economicamente importantes para a pesca da região como larvas de moluscos, crustáceos e peixes (Paranaguá e Eskinazi-Leça 1985; Paranaguá et al. 1999). De acordo com Lima e Quinamo (2000), a pesca na região é basicamente artesanal, envolvendo cerca de cinco mil pescadores e pescadeiras que desenvolvem atividades de subsistência e comercial. Estima-se que perto de $50 \%$ de toda a pesca marítima do Estado de Pernambuco é proveniente dos municípios cujos núcleos pesqueiros têm seus portos voltados para o Canal de Santa Cruz, destacando-se em produtividade o município de Itapissuma.

Apesar de toda relevância ecológica, econômica e educativa, o uso e manejo desordenado dos recursos naturais vêm causando impactos altamente negativos, já percebidos e compartilhados pela população ribeirinha. As intensas e diversificadas ações antrópicas sofridas pelo sistema, tais como urbanização, crescente densidade populacional, aterros imobiliários, desmatamentos dos manguezais, turismo, contaminação do ecossistema por efluentes industriais e domésticos sem tratamento, atividades pesqueira legal e ilegal vêm comprometendo suas riquezas naturais. Neste 
PARANAGUÁ, M. N. et. all. Educação ambiental como instrumento de gestão comunitária de ecossistemas manguezais do canal de Santa Cruz (PE, Brasil).

caso, a pressão a que está sujeito o ecossistema manguezal vem se constituindo em uma ameaça de vida às populações que habitam estas áreas.

Este trabalho apresenta uma síntese das experiências realizadas nos manguezais do Canal de Santa Cruz, Pernambuco - Brasil, objetivando a formação de competências locais para a avaliação e monitoramento das condições ambientais, preparando grupos para o exercício de atividades empreendedoras ligadas à preservação de ecossistemas costeiros que constituem a base de seu sustento tradicional.

\section{MATERIAL E METODOS}

Ao longo do período compreendido entre os anos de 2000 e 2001 foram desenvolvidos programas de educação ambiental, englobando 80 jovens - filhos de pescadores em sua maioria, com idade entre 16 e 21 anos, - provenientes dos municípios de Itamaracá, Itapissuma e Igarassu, comunidades ribeirinhas ao Canal de Santa Cruz. Esse trabalho enfoca os resultados referentes às metodologias de educação ambiental desenvolvidas através de oficinas incorporadas aos Programas "Guias do Litoral I", "Guias do Litoral II" e "O Manguezal em Nossa Casa" (Tabela 1). Antes do início dos trabalhos de educação ambiental foi realizado o reconhecimento da área e estreitamento de relações com as comunidades locais participantes, através de palestras nas associações de pescadores e de moradores dos municípios envolvidos, nas quais houve exposição dos objetivos do trabalho e discussão das sugestões dos ouvintes.

Os Programas "Guias do Litoral I" e "Guias do Litoral II" objetivaram formação de jovens capazes de atuar na multiplicação de informações e ações de conservação ambiental junto às comunidades locais e turísticas, constituindo-se numa atividade geradora de emprego e renda. Esses programas foram desenvolvidos em três módulos de ação. Nos dois primeiros módulos, o objetivo específico foi desenvolver nos atores o interesse pelo patrimônio histórico-cultural, tais como Museus, Fortes e Engenhos, e pelas riquezas naturais, principalmente áreas de manguezal. No terceiro módulo os estudantes desenvolveram atividades de identificação dos elementos naturais constituintes do ecossistema manguezal e de seu funcionamento, de forma que os jovens desenvolveram uma maior capacidade de conscientização dos principais problemas ambientais enfrentados pelas comunidades locais. No decorrer desses módulos, foram oferecidas aos jovens oficinas com temas ligados à biota do manguezal, aos processos ecológicos e à importância sócio-econômica do ecossistema, procurando sempre preservar os conhecimentos tradicionais da comunidade.

No programa "O Manguezal em Nossa Casa", as atividades e oficinas foram realizadas com o objetivo de se estabelecer a formação de jovens capazes de reconstituir e/ou recuperar pequenas áreas de manguezal no entorno de suas casas, através do replantio de mudas de mangue-vermelho Rhizophora mangle L. em habitações localizadas em áreas adjacentes ao manguezal.

\section{RESULTADOS E DISCUSSÃO}

Para abordagem dos temas procurou-se seguir os princípios norteadores da educação ambiental. Segundo Matsushima (1989), esse trabalho comporta uma parte filosófica e metodológica; outra de informações ambientais tratadas de modo multidisciplinar, interdisciplinar e holístico; e, finalmente, um conjunto de atividades práticas transformadoras do meio e da pessoa. Munhoz (1991) enfatiza também o papel da educação ambiental na mudança de curso do processo de degradação antrópica do meio ambiente, pois, segundo ela, é através da educação ambiental que se pode introduzir a preocupação permanente e a busca de entendimento sobre os fatores que interferem nessa situação, nos aspectos sócio-econômicos, políticos e ecológicos. Abordando aspectos de educação ambiental no Nordeste brasileiro, pode-se destacar os trabalhos de Paranaguá et al. (2003), Moreno et al. (2003) e Melo Junior et al. (2002).

As aulas eram iniciadas em clima de diálogo, tentando identificar as informações prévias dos alunos e seus objetivos em relação à proposta de trabalho. Era aplicado 
PARANAGUÁ, M. N. et. all. Educação ambiental como instrumento de gestão comunitária de ecossistemas manguezais do canal de Santa Cruz (PE, Brasil).

também um questionário para avaliar a percepção ambiental e detectar as habilidades artísticas e intelectuais, visando prever o nível de dinamização das aulas. Após as aulas teóricas, os alunos foram divididos em grupos para o desenvolvimento de atividades em campo, tais como coleta de material e observação de problemas locais como desmatamento, poluição e demais impactos antrópicos (Tabela 1).

Os conhecimentos construídos pelos grupos podem ser aferidos e avaliados através dos produtos confeccionados durante os módulos de formação (Tabela 2):

1. Confecção de cartilhas e apostilas didáticas: mostrou-se importante para a sistematização e fixação das informações adquiridas, tanto pelo embasamento teórico contido nas apostilas como pela apropriação dos conhecimentos por parte dos alunos, através da produção das cartilhas. Essa apropriação dos conhecimentos se torna mais eficaz quando o educando começa a formar seus próprios conceitos e tirar suas próprias conclusões sobre as informações adquiridas, mostrando que não houve apenas um mero repasse de conhecimento, mas sim uma perfeita transformação/adequação do saber científico em/ao saber popular.

2. Elaboração do Kit Mangue: foram elaborados kits didáticos, denominados de Kit Mangue, utilizando exemplares da fauna acompanhante das pescarias locais, que não são utilizados pelos pescadores, e de partes vegetativas da flora do manguezal (galhos, folhas, flores e frutos). Todos os representantes da fauna e da flora do kit eram acompanhados por fichas de identificação. Cada ficha continha desenhos feitos pelos próprios atores, nomes científicos e posição sistemática, alguns comentários sobre a ecologia e importância sócio-econômica das espécies para a região do Canal de Santa Cruz.

3. Histórias em quadrinhos: com relação a essa atividade, procurou-se aliar a criatividade dos alunos ao conhecimento formal adquirido. O estímulo à imaginação rendeu frutos consistentes, o que pôde ser observado nas histórias criadas, as quais misturaram muito bem humor e coerência com os temas trabalhados em sala-de-aula. Os títulos utilizados nessas histórias ilustram bem este fato, tais como: a) Um Casal Apaixonado: Suruany e Surubim, texto que falava do ciclo de vida do sururu Mytella charruana, molusco de grande importância comercial na região, que, após um período de relacionamento, produzem muitos filhotes, retratando, assim, a reposição desses bivalves nos ecossistemas estuarinos; b) O Namoro dos Siris, que abordou a vida reprodutiva de um casal de siris Callinectes danae, enfatizando a dispersão das larvas no estuário, a sucessão de estágios larvais, a procura de proteção entre as raízes de mangue-vermelho (Rhizophora mangle) e a busca por alimento; c) A Reprodução e a Luta pela Sobrevivência, que retratou a importância do manguezal para o desenvolvimento de ovos e larvas de peixes.

4. Você sabia que a minha vida começa no plâncton?: através da observação de amostras de zooplâncton coletadas pelos alunos, eles tomaram consciência da ocorrência de larvas de moluscos, crustáceos e peixes que ali vivem durante uma fase da vida. $\mathrm{Na}$ elaboração das caixas zoológicas enfatizou-se o ciclo de vida de determinados organismos como ostras e caranguejos, demonstrando que a manutenção do equilíbrio do ecossistema como um todo é fundamental para a interação harmoniosa entre homem e meio ambiente. Este conhecimento despertou nos atores a consciência da importância daquele ambiente, tornando-os aptos para intervir individual ou coletivamente na resolução dos problemas ambientais.

5. Produção e replantio de mudas de mangue: o mangue vermelho (Rhizophora mangle) foi escolhido por ser a espécie mais freqüentemente encontrada na região. Oficinas de produção de mudas foram desenvolvidas pelos atores em suas próprias casas, onde foram mantidas até o momento do replantio. Os propágulos foram coletados no solo, os quais ainda não estavam fixos nem enraizados; algumas vezes as árvores eram balançadas com o intuito de fazer cair aqueles propágulos prestes a se desprenderem da árvore-mãe. As coletas dos propágulos foram importantes para 
PARANAGUÁ, M. N. et. all. Educação ambiental como instrumento de gestão comunitária de ecossistemas manguezais do canal de Santa Cruz (PE, Brasil).

familiarização dos alunos com o ecossistema manguezal. As mudas foram regadas diariamente durante três meses, e posteriormente, foram replantadas.

Para o replantio dessas mudas, foram escolhidos locais devastados próximos àquele onde ocorreu a coleta das sementes. Segundo Schaeffer-Novelli (1995), dentre os critérios adotados, quando se faz necessário uma intervenção para a restauração de área degradada, é a consideração das espécies dominantes, cujas mudas ou sementes deverão ser preferencialmente da mesma área ou de áreas adjacentes que apresentam características ambientais semelhantes às da área a ser reflorestada. Assim, as mudas foram replantadas durante o período de maré baixa, procurando ao máximo locais onde se encontravam árvores da mesma espécie, e obedecendo a distribuição no sedimento observada para as espécies trabalhadas.

Durante o desenvolvimento dos Programas, a grande preocupação foi desenvolver habilidades e competências nos atores, tornando-os capazes de compreender o ecossistema aquático como um sistema dinâmico devendo-se, portanto, não considerar indivíduos isoladamente, e sim, as inter-relações existentes entre as várias espécies e o meio.

A maioria dos alunos conseguiu fixar os princípios científicos da constituição, do funcionamento e de como se processa a transferência de energia nos ecossistemas manguezais. Aliado a isso, foi observado durante a execução das atividades vinculadas às oficinas, um elevado conhecimento tradicional sobre o ecossistema manguezal por parte dos jovens. De fato, esta última particularidade deve-se às condições sócio-ambientais nas quais os jovens estão inseridos. No município de Itapissuma (PE), em particular, Pereira et al. (2006) observaram que os jovens pertencentes a esta localidade apresentam um conhecimento sobre manguezais superior ao registrado por jovens de Olinda e Recife. Este fato foi apontado pelos autores como sendo resultante da maior inserção dos jovens de Itapissuma nos ecossistemas manguezais, em comparação com os dos outros municípios avaliados.

É conhecido que as comunidades cuja sobrevivência depende diretamente dos recursos naturais possuem um conhecimento empírico acumulado do ambiente que exploram. De acordo com Carneiro et al. (2008), que estudaram a etnoecologia dos pescadores de Itapissuma, os entrevistados possuem uma concepção ampla quanto aos benefícios do manguezal para os seres vivos, reconhecendo a importância deste ecossistema para suas vidas, especificamente quanto à sua biodiversidade e utilidade. Fato semelhante também foi descrito por Moura et al. (2008) e Souto e Martins (2009) para os conhecimentos etnoecológicos de pescadores e marisqueiras do Estado da Bahia.

Segundo Cunha et al (2000), programas de educação ambiental possibilitam a aquisição de conhecimentos e habilidades capazes de induzir mudanças de atitudes do homem em relação ao seu meio ambiente, com adoção de novas posturas individuais. Desta forma, espera-se que os conhecimentos formais adquiridos pelos jovens participantes do presente trabalho sejam aliados aos conhecimentos tradicionais quanto à importância dos manguezais da região, contribuindo para o uso sustentável e gestão ambiental desse ecossistema.

As parcerias formadas entre Universidade, Prefeitura e Colônia de Pescadores têm trazido resultados importantes no sentido de uma maior conscientização de como utilizar os recursos naturais disponíveis no manguezal. A comunidade tem participado ativamente nos movimentos relativos à conservação deste importante patrimônio natural e, além disso, temos conhecimento de que alguns jovens que participaram destas atividades estão atuando na área de turismo na região.

Por sugestão dos alunos, todo o material produzido foi doado para a Colônia de Pescadores, Escolas e Biblioteca da comunidade, podendo ser utilizado em atividades futuras. 


\section{AGRADECIMENTOS}

Os autores são gratos às Prefeituras de Igarassu e Itapissuma, à Colônia de Pesca Z-10 de Itapissuma, ao Centro Cultural de Itapissuma e ao Convento de Santo Antônio (Igarassu). Os Programas de Educação Ambiental apresentados neste trabalho contaram com o auxilio financeiro da Finep, CNPq, Comunidade Solidária - UNISOL e Universidade Federal Rural de Pernambuco.

\section{REFERÊNCIAS BIBLIOGRÁFICAS}

Briggs, J. C. 1996. Global Biogeography. Developments in Paleontology and Stratigraphy 14. Elsevier, Amsterdam.

Barros, H.; Eskinazi-Leça, E.; Paranaguá, M. N. 1999. Gestão comunitária de recursos naturais: ampliando competências locais para o tratamento sustentável da questão litorânea do Nordeste. Processos de Gestão e Políticas Públicas 5: 25-44.

Barros, H. M.; Eskinazi-Leça, E. 2000. Introdução. In: Barros, H. M.; Eskinazi-Leça, E.; Macedo, S. J.; Lima, T. (eds.). Gerenciamento Participativo de Estuários e Manguezais. Recife, Ed. Universitária da UFPE.

Carneiro, M. A. B.; Farrapeira, C. M. R.; Silva, K. M. E. 2008. O manguezal na visão etnoecológica dos pescadores artesanais do Canal de Santa Cruz, Itapissuma, Pernambuco, Brasil. Biotemas 21(4): 147-155.

Cunha, A.; Santos, F. L. B.; Guimarães, A.; Lino, M. 2000. A aplicação do programa de aulas "Descobrindo o Manguezal", na escola municipal Novo Pina. Recife, Mangrove 2000 (CD ROM).

Eskinazi-Leça, E.; Barros, H. M. 2000. Síntese Global e recomendações. In: Barros, H. M.; Eskinazi-Leça, E.; Macedo, S. J.; Lima, T. (eds.). Gerenciamento Participativo de Estuários e Manguezais. Recife, Ed. Universitária da UFPE.

Field, C. 1996. Rationale for restauration of mangrove ecosystems. In: Field, C. (ed.). Restauration of mangrove ecosystems, Okinawa.

Lima,T.; Quinamo, T. 2000. Características sócio-econômicas. In: Barros, H. M.; Eskinazi-Leça, E.; Macedo, S. J.; Lima, T. (eds.). Gerenciamento Participativo de Estuários e Manguezais. Recife, Ed. Universitária da UFPE.

Matsushima, K. 1989. Educação ambiental: uma concepção teórica e prática. I Fórum de Educação Ambiental, São Paulo.

Melo Júnior, M.; Almeida, V. L. S.; Barros, H. M.; Paranaguá, M. N. 2002. "O Manguezal em Nossa Casa": capacitação de jovens para monitoramento e recuperação de ecossistemas estuarinos no nordeste do Brasil. In: VI Workshop ECOLAB (CD ROM), Belém.

Moreno, M. C.; Redling, J. S. H.; Costa, J. O.; Costa, E. P. J. 2003. Educação ambiental como proposta de orientação aos pescadores artesanais de camarão no Parque Nacional de Jericoacoara - CE. In: VI Congresso de Ecologia do Brasil, Fortaleza.

Moura, F. B. P.; Marques, J. G. W.; Nogueira, S. E. M. 2008. "Peixe sabido, que enxerga de longe": Conhecimento ictiológico tradicional na Chapada Diamantina, Bahia.

Biotemas 21(3): 115-123.

Munhoz, T. 1991. Desenvolvimento sustentável e educação ambiental. Em aberto, $10(49), 63-64$. 
Paranaguá, M. N.; Eskinazi-Leça, E. 1985. Ecology of a northern tropical estuary in Brazil and technological perspectives in fishculture. In: Yáñez-Arancibia (ed.). Fish Comunity Ecology in Estuaries and Coastal Lagoons: Towards on Ecosystems Integration. Cidade do México.

Paranaguá, M. N.; Alves, M. S.; Almeida, V. L. S.; Melo Júnior, M. 2003. Oficina de capacitação para pescadores da Colônia Z-5 de São Francisco do Conde - Bahia. In: VI Congresso de Ecologia do Brasil, Fortaleza.

Paranaguá, M. N.; Neumann-Leitão, S.; Mello, R. L. S.; Coelho, P. A.; Vasconcelos-Filho, A.; Oliveira, A. E. 1999. Management in northeastern Brazil: faunal biodiversity. In: Brebbia, C. A. e Usó, J. L. (eds). Ecosystems and Sustainable Development II. Sothampton.

Pereira, E. M.; Farrapeira, C. M. R.; Pinto, S. L. 2006. Percepção e educação ambiental sobre manguezais em escolas públicas da região metropolitana do Recife. Rev.

eletrônica Mestr. Educ. Ambient. 17: 244-261.

Schaeffer-Novelli, Y. 1995. Manguezal: ecossistema entre a terra e o mar. São Paulo, Caribbean Ecological Research.

Schuler, C. A. B.; Andrade, V. C.; Santos, D. S. 2000. O manguezal: composição e estrutura. In: Barros, H. M.; Eskinazi-Leça, E.; Macedo, S. J.; Lima, T. (eds.).

Gerenciamento Participativo de Estuários e Manguezais. Recife, Ed. Universitária da UFPE.

Souto, F. J. B.; Martins, V. S. 2009. Conhecimentos etnoecológicos na mariscagem de moluscos bivalves no Manguezal do Distrito de Acupe, Santo Amaro - BA. Biotemas 22(4): 207-218.

Vannucci, M. 1999. Os manguezais e nós: uma síntese de percepções. São Paulo, Edusp.

Tabela 1- Atividades desenvolvidas durante as oficinas de educação ambiental com seus respectivos temas e recursos utilizados.

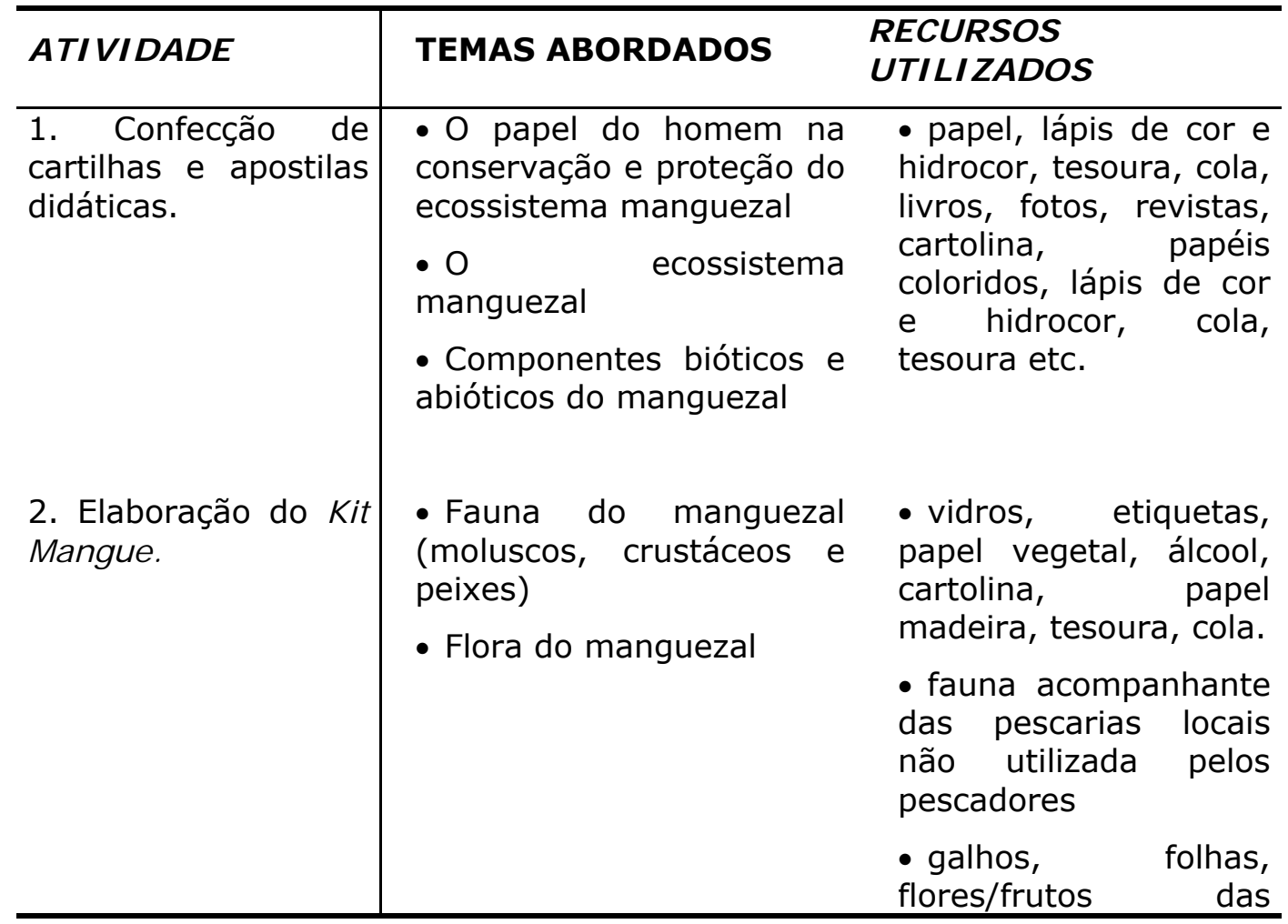


PARANAGUÁ, M. N. et. all. Educação ambiental como instrumento de gestão comunitária de ecossistemas manguezais do canal de Santa Cruz (PE, Brasil).

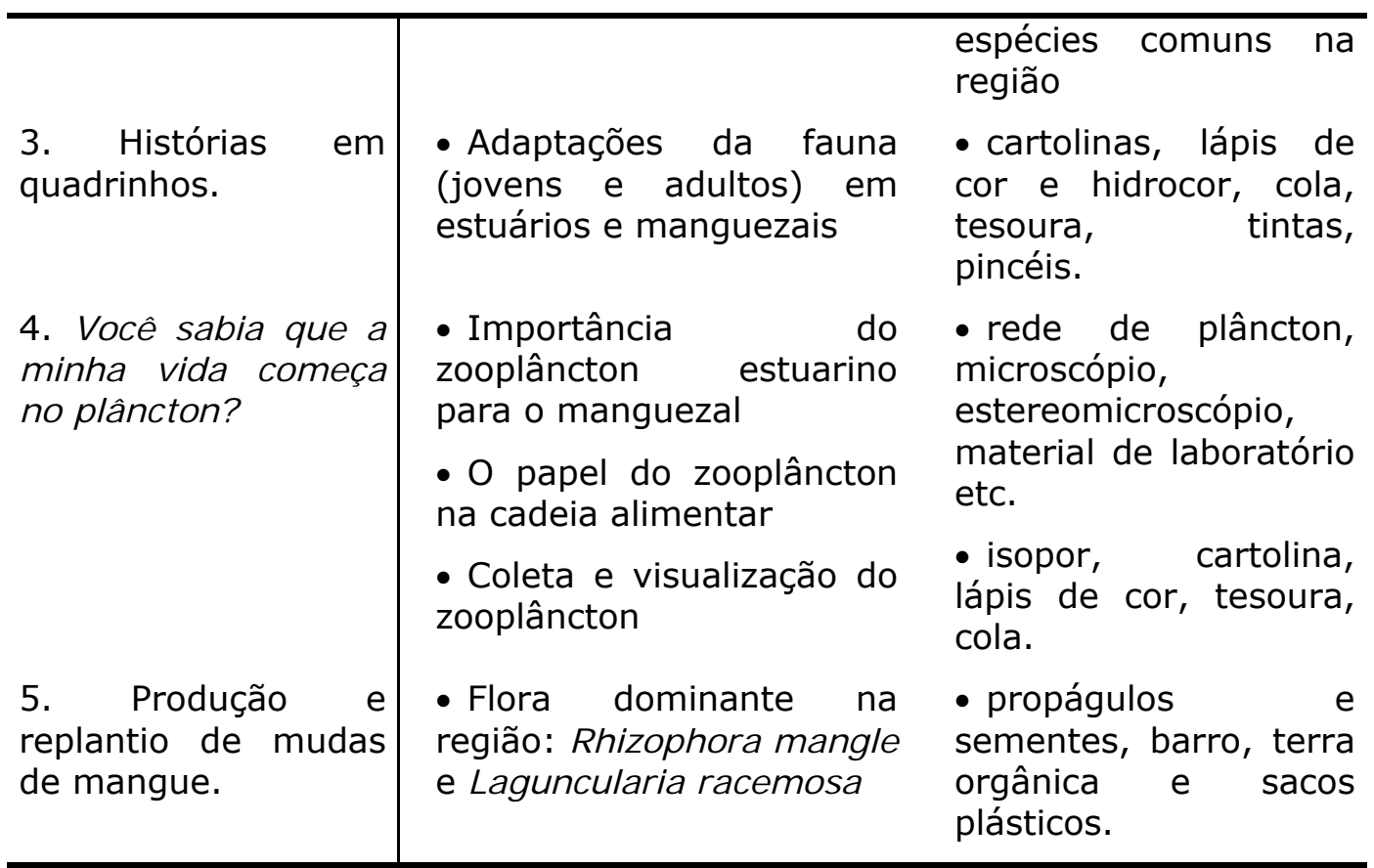

Tabela 2 - Atividades desenvolvidas durante as oficinas de educação ambiental com seus principais produtos.

\begin{tabular}{|c|c|}
\hline ATI VI DADE & PRINCIPAIS PRODUTOS \\
\hline $\begin{array}{l}\text { 1.Confecção de } \\
\text { cartilhas e apostilas } \\
\text { didáticas. }\end{array}$ & $\begin{array}{l}\text { - livreto com enredo trabalhado pelos alunos, } \\
\text { adequando-se assim à realidade local. } \\
\text { - quatro apostilas: O Ecossistema Manguezal, Os } \\
\text { Vegetais do Manguezal, Os Animais do Manguezal e A } \\
\text { Importância do Manguezal }\end{array}$ \\
\hline $\begin{array}{l}\text { 2. Elaboração do Kit } \\
\text { Mangue. }\end{array}$ & $\begin{array}{l}\text { - Coleção didática da fauna local. } \\
\text { - Confecção de exsicatas com as espécies mangue. } \\
\text { - Fichas de identificação com desenhos e informações } \\
\text { ecológicas. }\end{array}$ \\
\hline $\begin{array}{l}\text { 3. Histórias em } \\
\text { quadrinhos. }\end{array}$ & $\begin{array}{l}\text { - histórias elaboradas pelos alunos, enfatizando os } \\
\text { temas de uma forma lúdica e de fácil compreensão. }\end{array}$ \\
\hline $\begin{array}{l}\text { 4. Você sabia que a } \\
\text { minha vida começa } \\
\text { no plâncton? }\end{array}$ & $\begin{array}{l}\text { - caixas zoológicas mostrando o ciclo de vida de alguns } \\
\text { representantes da fauna, com o título: "Você sabia que } \\
\text { minha vida começa no plâncton?" }\end{array}$ \\
\hline $\begin{array}{l}\text { 5. Produção e } \\
\text { replantio de mudas } \\
\text { de mangue. }\end{array}$ & $\begin{array}{l}\text { - mudas e plântulas, as quais foram cultivadas e } \\
\text { replantadas }\end{array}$ \\
\hline
\end{tabular}

